\title{
Correction to: Insights into mud dragon morphology (Kinorhyncha, Allomalorhagida): myoanatomy and neuroanatomy of Dracoderes abei and Pycnophyes ilyocryptus
}

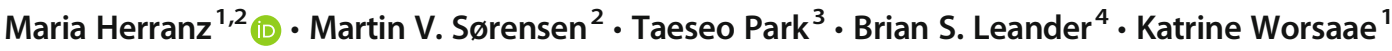 \\ Published online: 13 July 2020 \\ (C) Gesellschaft für Biologische Systematik 2020
}

\section{Correction to: Organisms Diversity \& Evolution https://doi.org/10.1007/s13127-020-00447-y}

The publisher regrets that the presentation of Fig. 8 in the original version of this article contained an error where all serotonergic somata, represented as blue circles in Fig. 8c, with associated labels 'vms' and 'vncs5' were omitted during the publication process. The original article has been corrected.

Publisher's note Springer Nature remains neutral with regard to jurisdictional claims in published maps and institutional affiliations.

The online version of the original article can be found at https://doi.org/ 10.1007/s13127-020-00447-y

Maria Herranz

maria.herranz@bio.ku.dk; mariaherranzm@gmail.com

1 Department of Biology, University of Copenhagen,

Copenhagen, Denmark

2 Natural History Museum of Denmark, University of Copenhagen, Copenhagen, Denmark

3 National Institute of Biological Resources, Incheon, South Korea

4 Departments of Zoology and Botany, University of British

Columbia, Vancouver, Canada 